\title{
Posterior deviation of left ventricular outflow tract septal components without ventricular septal defect
}

Süheyla Özkutlu, N Kürşat Tokel, Muhsin Saraçlar, Dursun Alehan, Yurdakul Yurdakul, Şevket Ruacan

\begin{abstract}
Objective-To describe 11 patients with narrowing of the left ventricular outflow tract caused by angular posterior deviation of both the outlet septum and the upper part of trabecular septum, which was diagnosed by cross sectional echocardiography in all and confirmed by angiocardiography in seven.

Results-Four patients had a subaortic systolic pressure gradient ranging from 23 to $70 \mathrm{~mm} \mathrm{Hg}$ by Doppler echocardiography; cardiac catheterisation showed a significant (60 and $104 \mathrm{~mm} \mathrm{Hg}$ ) systolic pressure gradient in two. In four cases aortic regurgitation and two tricuspid pouches were shown by Doppler echocardiography, angiocardiography, or both. Four cases had a ridge at the angulation point on echocardiographic examination. Three patients were operated on for systolic pressure gradients of the left ventricular outflow tract and one for severe aortic regurgitation. There was proliferation of collagen-rich fibrous tissue in the subendocardial region on histopathological examination of the myectomy material. A ventricular septal defect had been diagnosed previously by contrast echocardiography in one patient; thus ventricular septal defects may close spontaneously over a period of time including fetal life. A subaortic ridge was detected in one patient at follow up.

Conclusions-Deviation of the outlet and trabecular septa should be considered as a cause of ventricular outflow tract obstruction even when no ventricular septal defect is present.
\end{abstract}

(Heart 1997;77:242-246)

Keywords: interventricular septum; subaortic stenosis; aortic regurgitation
Left ventricular outflow tract obstruction is generally caused by subvalvar membranous or fibromuscular stenosis (fixed subvalvar $Q$ stenosis), hypertrophic cardiomyopathy, and, के rarely, cardiac tumours. ${ }^{1}$ In some cases with $\overrightarrow{0}$ ventricular septal defect, associated fibrous obstruction or septal malalignment may lead $\vec{\omega}$ to left ventricular outflow tract obstruction, and the obstruction may be more apparent fol- : lowing surgical closure of the ventricular septal defect. ${ }^{2-5}$ However, we have encountered some is patients with angular narrowing of the left ven- $\hat{N}$ tricular outflow tract caused by posterior devi- 윽 ation of both outlet and upper part of trabecular ventricular septa without ventricu- $\bar{z}$ lar septal defect. ${ }^{6}$ We therefore investigated these cases further.

\section{Methods}

Eleven patients who had angular posterior deviation of both outlet and upper trabecular ventricular septa, without ventricular septal defect, were examined between March $1992 \stackrel{\mathbb{Q}}{2}$ and January 1996. Seven had isolated poste- $\overrightarrow{\vec{O}}$ rior deviation of outlet and trabecular septum, $\frac{3}{3}$ but two had pulmonary valvular stenosis, and two coarctation of the aorta in addition (tables? 1 and 2).

Cross sectional and Doppler echocardiographic examination was performed using Toshiba SSH $60 \mathrm{~A}$ and Toshiba Sonolayer 3 $160 \mathrm{~A}$ equipment with $2.5,3.75$, and 8 $5.0 \mathrm{MHz}$ transducers. The standard parasternal long axis, subcostal long and short axes, 응 apical two- and four-chamber views, and suprasternal views were used for echocardiographic recordings.

The systolic pressure gradient of the left O ventricular outflow tract was measured in all $\mathbb{O}$ the patients. The severity of the left ventricular outflow tract obstruction was assessed $O$ echocardiographically by using the ratio of the 0 diameters of the left ventricular outflow tract

Y Yurdakul

Department of

Pathology, Hacettepe

University Faculty of

Medicine, Ankara,

Turkey

S Ruacan

Correspondence to:

Dr Süheyla Özkutlu,

Department of Paediatric

Cardiology, Hacettepe

University Faculty

Sihhiye/Ankara, Turkey.

Accepted for publication

11 November 1996

Table 1 Echocardiographic data of the patients with septal deviation

\begin{tabular}{|c|c|c|c|c|c|c|c|c|c|c|c|}
\hline Case No & 1 & 2 & 3 & 4 & 5 & 6 & 7 & 8 & 9 & 10 & 11 \\
\hline $\begin{array}{l}\text { Aortic systolic gradient } \\
(\mathrm{mm} \mathrm{Hg})\end{array}$ & 70 & $<10$ & 30 & $<10$ & $<10$ & 10 & 58 & $<10$ & 10 & 23 & $<10$ \\
\hline Aortic regurgitation & + & - & - & + & - & - & + & - & + & - & - \\
\hline Formation of ridge & - & - & + & - & - & + & - & - & - & + & + \\
\hline Width of IVS/BSA & $\mathrm{N}$ & $\mathrm{N}$ & I & $\mathrm{N}$ & $\mathbf{N}$ & I & I & $\mathrm{N}$ & $\mathbf{N}$ & $\mathbf{N}$ & $\mathbf{N}$ \\
\hline Tricuspid pouch & - & - & - & - & - & + & - & - & - & - & - \\
\hline Flutter of aortic valve & - & - & + & + & - & - & + & - & + & - & + \\
\hline Additional anomalies & - & - & CoA & - & $\begin{array}{l}\text { PS } \\
\text { AVP }\end{array}$ & PS & CoA & - & - & - & - \\
\hline
\end{tabular}

AVP, aortic valve prolapsus; BSA, body surface area; CoA, coarctation of aorta; I, increased; IVS, interventricular septum PS, pulmonary stenosis. 
Table 2 Catheterisation data of the patients with septal deviation

\begin{tabular}{|c|c|c|c|c|c|c|c|c|c|c|c|}
\hline Case No & 1 & $2^{*}$ & 3 & 4 & 5 & 6 & 7 & $8^{*}$ & 9 & $10^{*}$ & $11^{\star}$ \\
\hline $\begin{array}{l}\mathrm{LV}(\mathrm{mm} \mathrm{Hg}) \\
\text { Aorta }(\mathrm{mm} \mathrm{Hg}) \\
\text { Aortic gradient }(\mathrm{mm} \mathrm{Hg}) \\
\text { Aortic regurgitation } \\
\text { Additional anomalies }\end{array}$ & $\begin{array}{l}180 \\
120 / 64 \\
60 \\
\mathrm{II}^{\circ} \\
\text { No }^{\circ}\end{array}$ & & $\begin{array}{l}90 / 70 \\
? \\
\text { No } \\
\text { CoA }\end{array}$ & $\begin{array}{l}110 \\
110 / 63 \\
0 \\
\text { III }^{\circ} \\
\text { No }\end{array}$ & $\begin{array}{l}130 \\
130 / 88 \\
0 \\
\text { No } \\
\text { PS } \\
\text { AVP }\end{array}$ & $\begin{array}{l}110 \\
100 / 60 \\
10 \\
\text { No } \\
\text { PS }\end{array}$ & $\begin{array}{l}220 \\
116 / 63 \\
104 \\
\mathrm{II}^{\circ} \\
\operatorname{CoA}\end{array}$ & & $\begin{array}{l}125 \\
125 / 63 \\
0 \\
\mathrm{II}^{\circ} \\
\text { No }\end{array}$ & & \\
\hline Tricuspid pouch & No & & No & No & + & + & No & & No & & \\
\hline
\end{tabular}

${ }^{\star}$ Catheterisation was not performed; AVP, aortic valve prolapse; CoA, coarctation of aorta; PS, pulmonary stenosis; LV, left ventricle.

and the ascending aorta (LVOT/AAo). Measurements of the diameters of the left ventricular outflow tract proximal to the aortic valve and of the ascending aorta distal to the aortic cusps were made from parasternal

Figure 1 Standard and long axis views.

Echocardiograms during systole (above), diastole (middle), and schematic illustration of middle (below). Figure indicates posterior deviation of both outlet (dotted) and trabecular septa and trabecular septal crest (lower arrow). $L V$, left ventricle; $R V$, right ventricle; $L A$, left atrium, Ao, aorta; IVS, interventricular septum. modified parasternal
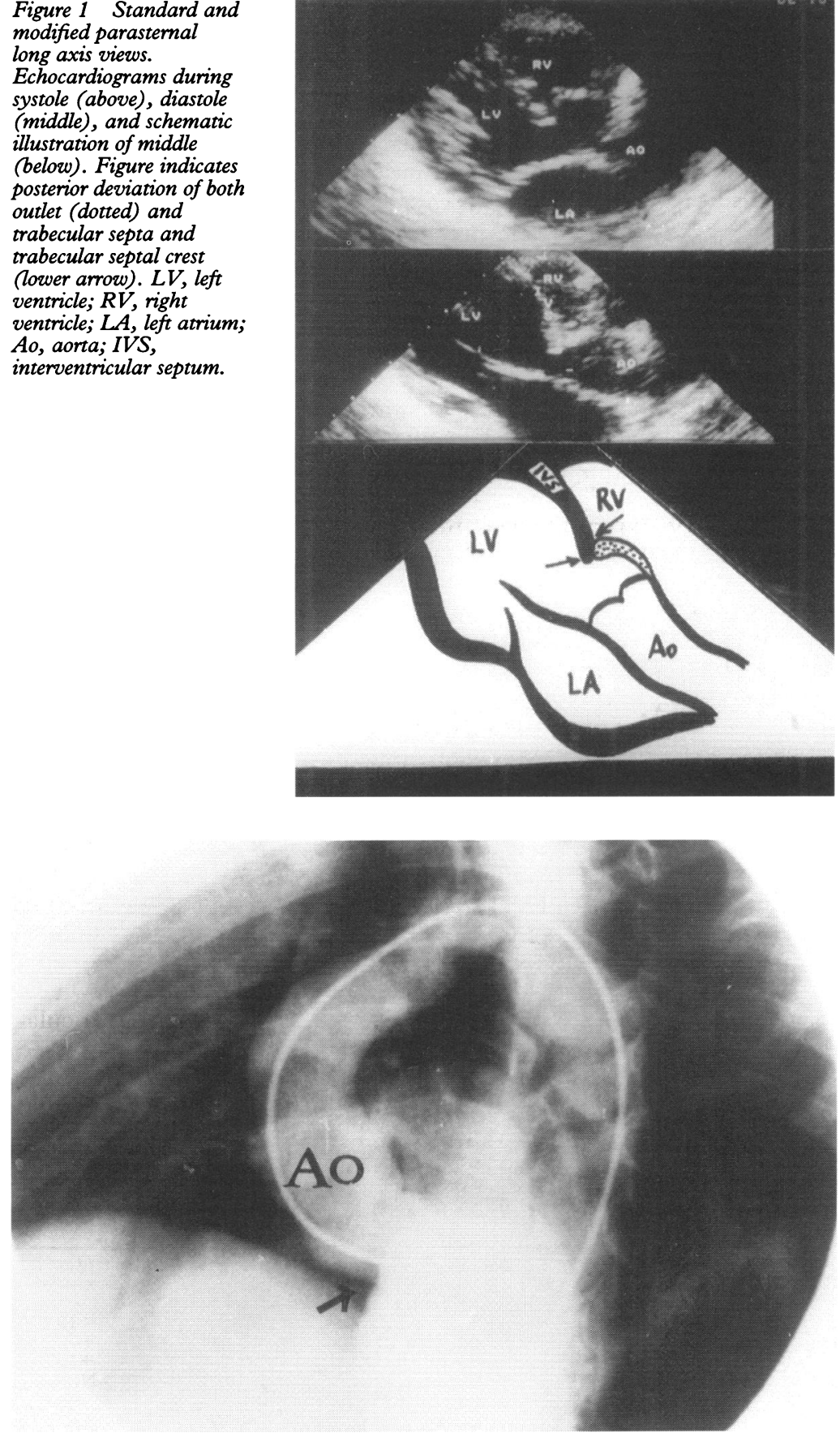

Figure 2 Left ventricular angiocardiogram in the long axis view. Arrow indicates the angulation between outlet and trabecular septa. The portion between the arrow and aortic valve is the outlet septum. Ao, aorta. echocardiographic long axis views during systole. $^{7}$

Cardiac catheterisation was performed in seven patients (table 2). After obtaining haemodynamic and oxygen saturation data, angiograms were made in long axis $\left(60^{\circ}\right.$ left anterior oblique view combined with $30^{\circ}$ craniocaudal angulation) and in the four-chamber views $\left(45^{\circ}\right.$ left anterior oblique view combined with $30^{\circ}$ craniocaudal angulation).

\section{Results}

The age range of the patients was between 3 and 19 years (median 8 years) at the time septal deviation was diagnosed. Although four patients (cases 2, 5, 9, and 11) had no symptoms, chest pain and palpitation were the most common symptoms in the others. There were no murmurs in one patient (case 2) and electrocardiography was normal in seven. Four patients had left ventricular hypertrophy (cases 3, 7, 8, and 10) and one had strain pattern (case 3). Cardiomegaly was found in three patients on $x$ ray examination (cases 4,5 , and 10).

On echocardiographic examination both outlet and upper trabecular septa were posteriorly deviated, and the outlet septum joined the trabecular septum on the right ventricular side of the septum in this entity. In most of the patients, the outlet septum did not join the trabecular septum at its crest, but inserted more apically on the right ventricular side (fig 1; cases $1,3,4,5,7,9$, and 11). This posterior deviation of outlet and upper trabecular septum creates an angle and the left ventricular outflow tract may be obstructed (figs 1,2 , and 3 ). This situation is best evaluated by echocardiography in parasternal (including modified parasternal) and subcostal long axis views (figs 1 and 3). The thickness of the interventricular septum in relation to body surface area was normal in eight patients, but abnormal in three (table 1). Four patients had systolic gradients ranging from 23 to $70 \mathrm{~mm} \mathrm{Hg}$, but the others did not have subaortic systolic pressure gradients. Four cases also had a subaortic ridge at the point of angulation. Other echocardiographic findings in the cases are shown in table 1 .

Cardiac catheterisation showed significant (60 and $104 \mathrm{~mm} \mathrm{Hg}$ ) subaortic systolic pressure gradients in two patients (cases 1 and 7) as detected by Doppler echocardiography. In case 3, it was not possible to measure the left ventricular outflow tract gradient by catheter since the patients also had severe coarctation and the catheter did not pass through. Four 


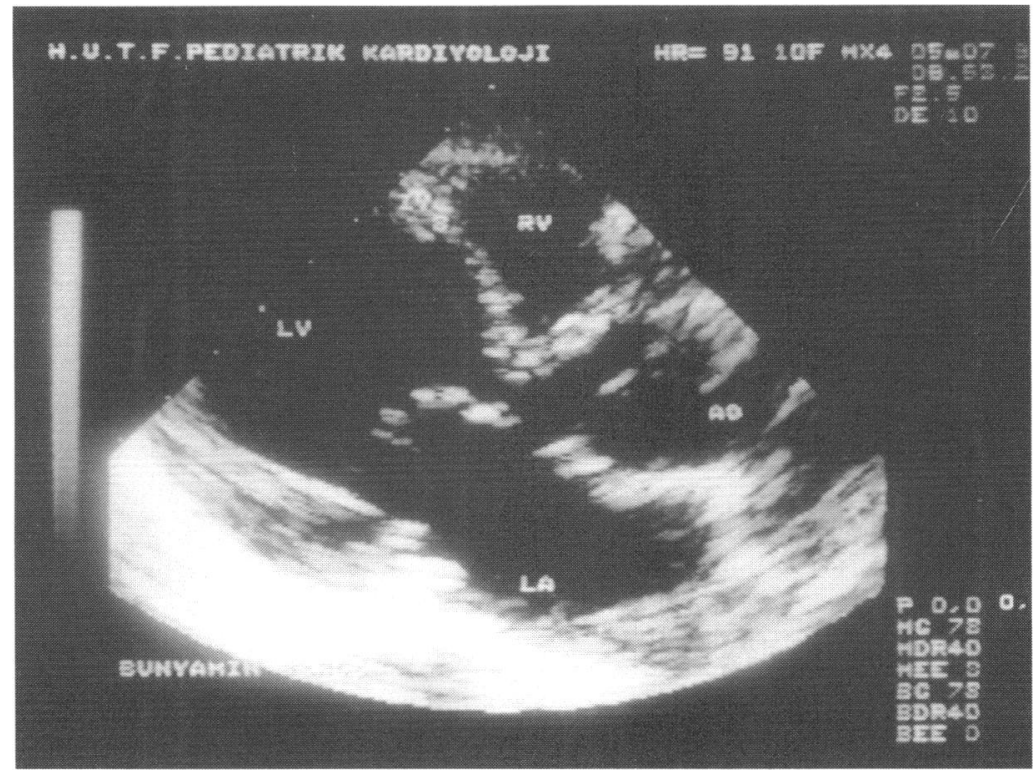

Figure 3 Parasternal long axis view of another case. Angular posterior deviation of both outlet and upper trabecular septa is clearly seen. $L V$, left ventricle; $L A$, left atrium; $R V$, right ventricle; Ao, aorta.

A
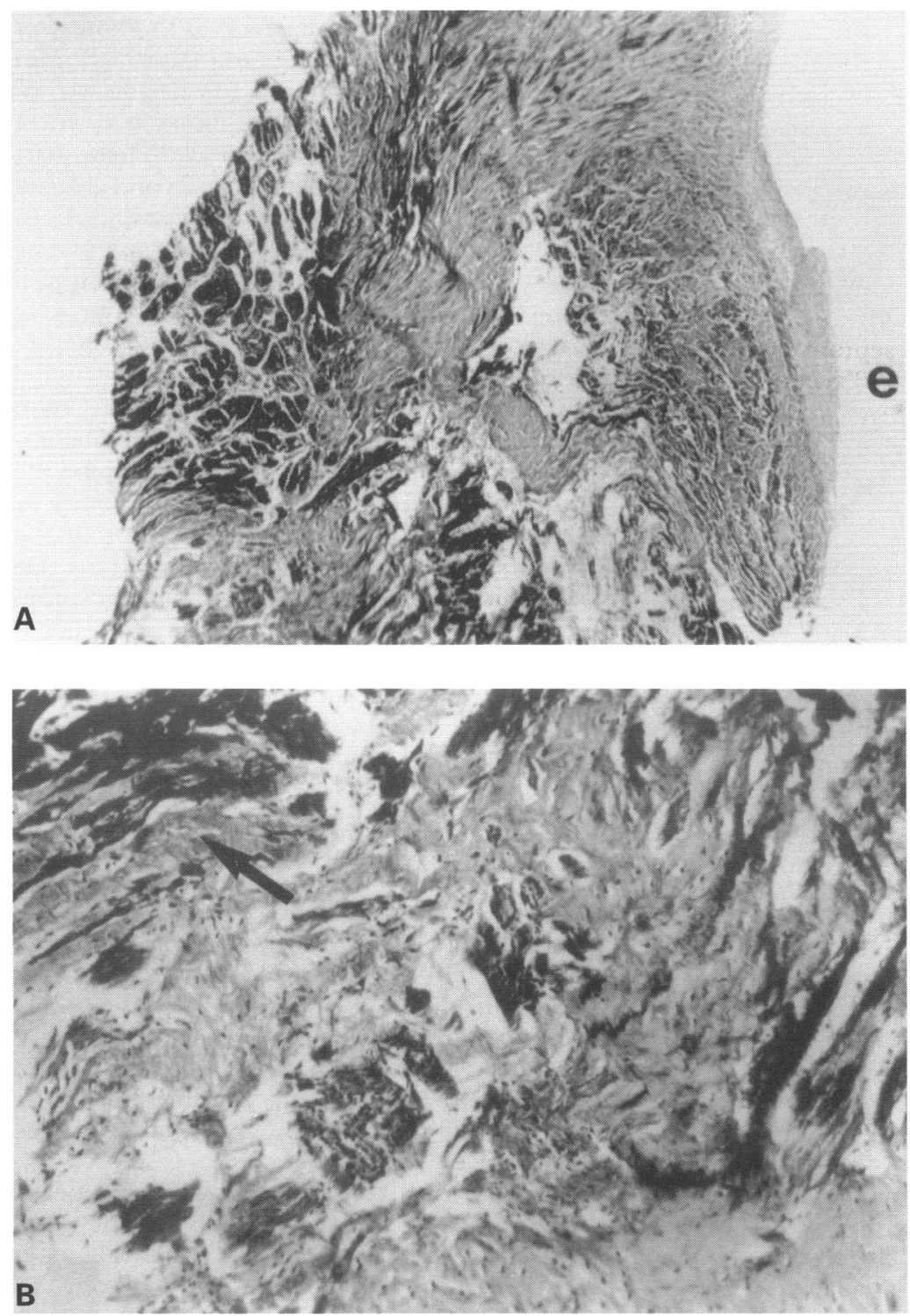

Figure 4 (A) Section of the biopsy specimen. Slightly thickened epicardium (e) and markedly distorted myocardial tissue replaced by irregular bands of fibrosis are observed (Masson's trichrome stain, $\times 109$ ). (B) Higher magnification shows scattered myocardial fibers (arrow) trapped in collagenous fibrous tissue (Masson's trichrome, $\times 435$ ). patients had aortic regurgitation (cases $1,4,7$, and 9) and two (cases 5 and 6) had a pouch of an accessory tricuspid valve (table 2 ).

Four of the patients (cases 1, 3, 4, and 7) were operated on.

In 1989, a subaortic ridge resection was done in case 1 because of a $60 \mathrm{~mm} \mathrm{Hg}$ systolic gradient at the left ventricular outflow tract. $\stackrel{\mathbb{D}}{\mathbb{D}}$ Previously undetected posterior deviation of? the outlet and trabecular septa was diagnosed $\overrightarrow{\vec{F}}$ by echocardiography postoperatively in March $\frac{\text { T }}{0}$ 1992. Left ventricular outflow tract pressure gradients of 70 and $60 \mathrm{~mm} \mathrm{Hg}$ were obtained $\overline{\bar{c}}$ by Doppler echocardiography and cardiac $\vec{\mathbb{}}$ catheterisation, respectively. Myectomy was performed at reoperation. Unfortunately after $\stackrel{\infty}{\infty}$ reoperation, obstruction of the left ventricular $\overrightarrow{0}$ outflow increased gradually and again reached $\overrightarrow{\vec{H}}$ $70 \mathrm{~mm} \mathrm{Hg}$ by Doppler echocardiography.

A successful myectomy and resection of

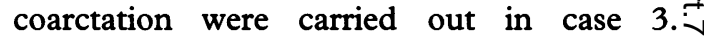
Doppler echocardiography did not show any ${ }_{\omega}$ left ventricular outflow tract obstruction.

Myectomy and coarctation resection were $\stackrel{N}{N}$ done in case 7 . We detected a $60 \mathrm{~mm} \mathrm{Hg}$ sys-음 tolic pressure gradient in the left ventricular outflow tract by Doppler echocardiography nine months later.

A patient without systolic pressure gradient $\stackrel{\Im}{\triangle}$ by Doppler echocardiography and cardiac 6 catheterisation (case 4) was operated on. because of severe aortic regurgitation (tables 1 응 and 2).

The remaining patients (cases 2, 5, 6, 8, 10, 응 and 11) have been closely followed up.

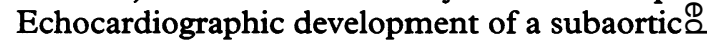
ridge without a pressure gradient in case 5 and $\vec{\circ}$ a $15 \mathrm{~mm} \mathrm{Hg}$ systolic pressure gradient at the 3 left ventricular outflow tract in case 8 have? been found during a three year follow up.

Microscopic examination of the tissue removed revealed slightly thickened and fibrotic endocardium (cases 4 and 7). There $\frac{-}{-}$ was proliferation of collagen-rich fibrous tissue 3 in the subendocardial region, with scattered $\delta$ myocardial fibres remaining trapped within this irregular fibrous mass (fig 4).

Figure 5 shows the relation between LVOT/AAo ratio measured by echocardiogra-을 phy and the subaortic pressure gradient

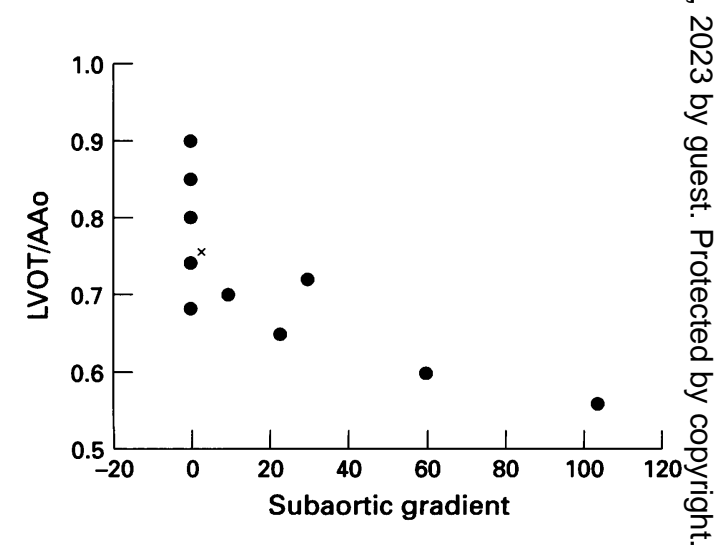

Figure 5 Relation between $L V O T / A A o$ ratio and subaortic pressure gradient measured by catheterisation and/or Doppler echocardiography. LVOT, left ventricular outflow tract; Aao, ascending aorta. $x$, two patients have the same results. 
assessed by echocardiographic and haemodynamic studies.

A ventricular septal defect had been diagnosed previously by physical examination and contrast echocardiography in one patient (case 6). We could not show a ventricular septal defect by angiocardiography three years after the contrast echocardiographic study. Two patients in whom no left to right shunt could be demonstrated haemodynamically and angiocardiographically (cases 5 and 6) had a pouch of an accessory tricuspid valve. One of these pouches was also demonstrated by echocardiography (case 6).

\section{Discussion}

A ventricular septal defect which appears to be caused by an abnormal displacement (deviation) of the outlet septum is called a ventricular septal defect of malalignment type. If the deviation is posterior, the left ventricular outflow tract may be narrowed. However, in the 11 cases presented by us and the four reported by Gewillig et al, a ventricular septal defect was absent. ${ }^{6}$ In the cases of Gewillig et al there was posterior malalignment between the membranous and muscular septum. According to their descriptions the membranous septum did not join the muscular septum at its crest, but inserted 15 to $26 \mathrm{~mm}$ more apically on the right ventricular side of the septum. However, in our patients there was an angular deviation of both the outlet and upper part of the trabecular septa. In fact, from the standpoint of posterior deviation of outlet septum our cases are more similar to the patient illustrated in figure 3 of the paper by Kitchiner et al. ${ }^{4}$ The outlet septum did not join the trabecular septum at its crest, but inserted more apically on the right ventricular side in most of our patients, as seen in fig 1 . In some other cases we could not show the trabecular crest.

In the cases with abnormal alignment of ventricular septal fragments, the term "malalignment" is generally used. However, some choose the term "deviation" to describe the morphology. Kitchiner states that this term would allow a more precise description of the structures involved and is less contentious. ${ }^{4}$ Therefore instead of "malalignment" we preferred "deviation".

In the differential diagnosis, we excluded cases showing anterior deviation of the outlet septum, which creates overriding of the aorta, and those with an interventricular septal prominence towards the left ventricular outflow tract caused by aberrant bands.

According to general concepts agreed on so far, malalignment or deviation of interventricular septum is encountered in patients with ventricular septal defect. Contrary to this belief, our cases did not have ventricular septal defects, so we assume that ventricular septal defects may close spontaneously over a period of time, which includes fetal life. ${ }^{89}$ In fact, in two of our patients (cases 5 and 6), a tricuspid pouch was shown by echocardiography or angiocardiography, suggesting spontaneous closure. Furthermore in our sixth patient, a ventricular septal defect had been documented by contrast echocardiographic examination a few years before we planned the present study. Another possibility may be that deviation develops directly by fusion of different fragments of the interventricular septum without producing a ventricular septal defect.

Posterior deviation of the outlet septum narrows the outflow tract of the left ventricle to some extent in patients with a ventricular septal defect. This may lead to an outflow systolic pressure gradient. However, the gradient may not be significant because of the left to right shunt through the ventricular septal defect when it is located beneath the outlet septum. ${ }^{10}$ Kitchiner et al reported that deviation of the outlet septum would create subaortic stenosis above the site of a surgically closed ventricular septal defect. ${ }^{4}$ Therefore during surgical intervention posterior deviation and related obstruction of the left ventricular outflow tract should be considered, and a proper outflow resection performed. ${ }^{45}$ Similar considerations should be applied to those patients without ventricular septal defect but with posterior deviation of outlet and trabecular septa causing significant left ventricular outflow tract obstruction.

We consider that this condition of posterior deviation of the ventricular septum is not very rare and is usually unnoticed. In fact figure 1 in the paper by Frommelt et al a good example of a sharply angulated interventricular septum and a ridge originating from the point of angulation is clearly seen, although only the subaortic fibrous ridge was mentioned in the text. ${ }^{11}$ In addition, in one of our cases (case 1) and one of Gewillig's the deviation was not noticed previously.

Iwahara et al reported that ventricular outflow tract obstruction is critical when the LVOT/AAo diameter ratio is 0.6 or less. ${ }^{7}$ In two of our cases this ratio was 0.6 or less and their gradients were higher than in the others (cases 1 and 7) (fig 5). On the other hand, removal of the septal deviation may be impracticable due to the close relation to the conduction system.

In four of our patients, a fibrous ridge was seen at the junction of the outlet and trabecular septa. We could not correlate the presence of a ridge and a systolic pressure gradient (table 1). Gewillig et al speculated that the occurrence of this lesion results from a specific anatomical substrate giving rise to abnormal flow dynamics. $^{612}$ This results in an excessive growth of fibrous tissue. Fibrous ridges have been associated with the presence of a longer outflow tract with increased aortic-mitral separation, a small outflow tract, malalignment type ventricular septal defect, the presence of a more apical septal fibrous ridge or apical muscular band, and doubly committed subarterial ventricular septal defect. ${ }^{4-61213}$ In one of our patients a fibrous ridge developed during follow up (case 5). This finding supports the findings of Kitchiner et al and Zielinsky et al. ${ }^{45}$

In two of our cases we found fibrotic changes in the myocardium at the region of deviation in histopathological examination of 
myectomy material. These findings were different from the changes in hypertrophic cardiomyopathy (fig 4).

Four of our patients had aortic insufficiency. This anomaly disturbs blood flow and frequently causes turbulence in the left ventricular outflow tract. Due to turbulence and increased flow rate, aortic regurgitation develops. ${ }^{14-18}$ Vries et al found an increase in the incidence of aortic regurgitation during a follow up study in 57 patients with subaortic stenosis. ${ }^{14}$ The incidence of aortic regurgitation in subaortic stenosis was $32 \%$ in the initial examination, but it increased to $54 \%$ at the end of four years follow up. Aortic regurgitation was related to subaortic pressure gradient in their study. However, we did not find any relation between the degree of aortic regurgitation and the subaortic pressure gradient. We believe that the progressive damage to the aortic valve is caused by the high velocity jet in the left ventricular outflow tract.

In conclusion, deviation of the outlet and trabecular septa should be considered as a cause of ventricular outflow tract obstruction even when no ventricular septal defect is present.

1 Bristow JD. Recognition of the left ventricular outflow tract obstruction. Circulation 1973;31:600-11.

2 Shore DF, Smalhorn J, Stark J, Lincoln C, De Leval MR. Left ventricular outflow tract obstruction coexisting with ventricular septal defect. Br Heart $f$ 1982;48:421-7.

3 Vogel M, Freedom RM, Brand A, Trusler GA, Williams GW, Rowe RD. Ventricular septal defect and subaortic $\mathrm{GW}$, Rowe RD. Ventricular septal defect and subaortic
stenosis: analysis of 41 patients. $A m \AA$ Cardiol 1983; 5tenosis: analys

4 Kitchiner D, Jackson M, Malaiya N, Walsh K, Peart I, Arnold $\mathrm{R}$, et al. Morphology of left ventricular outflow tract structures in patients with subaortic stenosis and a ventricular septal defect. Br Heart $\mathcal{F}$ 1994;72:251-60.
5 Zielinsky P, Rossi M, Haertel JC, Vitola D, Lucchese FA, Rodrigues $R$. Subaortic fibrous ridge and ventricular septal defect: role of septal "malalignment". Circulation 1987;75:1124-9.

6 Gewillig M, Daenen W, Dumoulin M, Hauwaert LVD. Rheologic genesis of discrete subvalvular aortic stenosis: a Doppler echocardiographic study. $7 \mathrm{Am}$ Coll Cardiol 1992;19:818-24.

7 Iwahara M, Ino T, Nishiomoto K, Park I, Akimato K, Shimozaki S, et al. Clinical features of aortic arch anomaly with "malalignment" ventricular septal defect. Ann Thorac Surg 1989;48:693-6.

8 Nir A, Driscoll DJ, Edwards WD. Intrauterine closure of membranous ventricular septal defects: mechanism of closure in two autopsy specimens. Pediatr Cardiol 1994; 15:33-7.

9 Hiraishi S, Agata Y, Nowatari M, Oguchi K, Misawa H, Hirota $\mathrm{H}$, et al. Incidence and natural course of trabecular ventricular septal defect: two-dimensional echocardiogra- $\bar{c}$ phy and color Doppler flow imaging study. $\mathcal{F}$ Pediatr 1992;120:409-15.

10 Vogel M, Smallhorn JF, Freedom RM, Coles J, Williams GW, Trusler GA. An echocardiographic study of the of association of ventricular septal defect and right ventricular muscle bundles with a fixed subaortic abnormality. Am $\mathcal{F}$ Cardiol 1988;61:857-60.

11 Frommelt MA, Snider AR, Bove FEL, Lupinetti FM. Echocardiographic assessment of subvalvular aortic $\omega$ stenosis before and after operation. $\mathcal{F} \mathrm{Am}$ Coll Cardiol 1992;19:1018-23.

12 Mertens L, Gewillig M. The formation of a discrete subvalvular outflow tract obstruction-at the interface $Y$ valvular outfow tract obstruction-at the interface between rheology and morphology. Eur Heart $\mathcal{F} 1996$; $\omega$ 17:809-10

13 Özkutlu S, Saraçlar M, Alehan D, Yurdakul Y, Fırat P, Tokel K. Subpulmonary and subaortic ridges in doubly committed subarterial ventricular defect: an echocardio- $O$ graphic study. Eur Heart $\mathcal{f}$ 1996;17:935-9.

14 Vries AG, Hess J, Witsenburg M, Frohn-Muldep IME, Bogers ADJJ, Boss E. Management of fixed subaortic stenosis: a retrospective study of 57 cases. $\mathcal{F} \mathrm{Am}$ Coll Cardiol 1992;19:1013-7.

15 Champspour G, Trusler GA, Mustard WT. Congenital discrete subvalvar aortic stenosis: surgical experience and $\vec{C}$ long term follow-up. Br Heart $\mathcal{F}$ 1973;35:343-7.

16 Douville EC, Sade RM, Crawford FA, Wiles HB. . Subvalvar aortic stenosis: timing of operation. Ann Thorac Surg 1990;50:29-34.

17 Jaumin P, Rubay J, Lintersmans J, Arena V, Matto A, Goenen $\mathrm{M}$, et al. Surgical treatment of subvalvular aortic stenosis. Long term results. $\mathcal{F}$ Cardiovasc Surg 1990; 31:31-5.

18 Kitchiner D, Jackson M, Malaiya N, Walsh K, Peart I, $\stackrel{\odot}{\Phi}$ Arnold $\mathrm{R}$. Incidence and prognosis of obstruction of the left ventricular outflow tract in Liverpool (1960-1991). $\bar{O}$ Br Heart $\mathcal{F}$ 1994;71:588-95. 